\title{
Jules Horowitz Reactor Project. Exploration tests concerning WIFI modules behaviour under gamma flux
}

\author{
S. Gaillot, B. Pouchin, J. G. Marques, I. López-Calle, F. J. Franco, and J. A. Agapito, Member IEEE
}

\begin{abstract}
Within the framework of experimental field on technologies developments for research reactors applications, an experimental program dedicated to electronics behaviour under flux has been performed on wireless (WIFI) modules. The interest of using the WIFI modules in an industrial facility is to limit and some cases to work without transmission lines between the experimental equipments in which sensors are embedded and the facility (i.e data acquisition room). The objectives of these tests were to determine the capabilities of WIFI modules to work in Nuclear Environment, to define the limitation due to the dose levels and to propose some adaptations in term of integration. These actions have been carried out on [2009-2010] period, in sharing collaboration between CEA (Commissariat à IEnergie Atomique et aux Energies Alternatives, France), ITN (Nuclear and Technological Institute, Portugal) and UCM (University Complutense of Madrid, Spain). The experimental program on WIFI modules took into account a first phase of data determination of dose levels based on Jules Horowitz Reactor environment. The second phase (performed by UCM and ITN) was dedicated to the selection of modules focused on commercial type (COTS approach). Then, irradiation tests of these modules using a ${ }^{60} \mathrm{Co}$ source and in the RPI reactor have been performed by ITN with UCM. The results obtained are presented and discussed. As conclusion, some recommendations are given.
\end{abstract}

Index Terms-Electronics, WIFI Modules, COTS, Gamma flux, Dose tolerance.

\section{INTRODUCTION}

In a nuclear environment, the use of electronics is limited due to the doses effects on the components. In this context, some studies are performed in order to characterise the dose tolerance of electronics, and to propose some adaptations in order to increase the capability to work under flux.

The objective of this present work is to determine the dose tolerance of commercially available wireless (WIFI) modules (the so-called "Components Off The Shelf", or COTS) in a nuclear environment, with gamma and neutron fluxes.

Manuscript sent to RADECS2011 on April, $29^{t h}, 2011$, revised on September, $16^{\text {th }}, 2011$

Stephan Gaillot is with CEA, DEN, DTN-STPA-LCIT, bat. 204, Cadarache, F-13108, Saint-Paul-lez-Durance, FRANCE. Phone: +33 (0) 442253165 - email: stephane.gaillot@cea.fr

Bernard Pouchin is with CEA, DEN, DER-SRJH, bat. 224, Cadarache, F-13108, Saint-Paul-lez-Durance, FRANCE. Phone: +33 (0) 442254971 - email: bernard.pouchin@cea.fr

Jose G. Marques is with the Instituto Tecnologico e Nuclear- Estrada Nacional 10, P-2686-953 Sacavem, PORTUGAL. Phone: +351 219946115 e-mail: jmarques@itn.pt

Isabel López-Calle, Francisco J. Franco, and Juan A. Agapito are with the Departamento de Física Aplicada III, Facultad de Físicas, Universidad Complutense de Madrid (UCM), 28040 Madrid, SPAIN. Phone: +34 91394 4434 - e-mail:agapito@fis.ucm.es).
The results obtained about electronics dose tolerance was dedicated firstly for research reactor applications (embedded electronics on irradiation device) but it can be extended to other nuclear facilities in which the use of electronics WIFI modules could be interesting (process control instrumentation on circuits with dose levels constraints).

This work has been performed on 2009-2010 period in sharing collaboration between CEA in France (input data determination), UCM in Spain (modules selection, module preparation, expertise after tests) and ITN in Portugal (gamma irradiation facility, research reactor).

\section{THE JHR FACILITY}

The Jules Horowitz Reactor (JHR-Materials Testing Reactor) is under construction in the south of France (Cadarache, Bouches du Rhone). This Nuclear Facility is dedicated to perform irradiation of materials, fuels in support of present (LWR) and futures power plants (Gen. V, fusion). It allows also producing radioisotopes for medical applications, namely ${ }^{99}$ Mo. This facility will offer to the international community interesting irradiation capabilities ( $15 \mathrm{dpa} /$ year at $100 \mathrm{MW}$ ) for core materials samples, high thermal neutron fluxes in the reflector for irradiation of fuels (corresponding to 8 times the neutron flux in a PWR). It will allow also a high flexibility in terms of experimental conditions, several irradiation locations in the core, in the reflector in fixed and also on movable locations (systems permitting to modify the distance between the sample and the core using pre-defined moving scenario). For different experimental issues, several thermal hydraulics conditions can be obtained (LWR (P\&B), HTR, SFR,).

In addition, some supports utilities (storage pools, hot cells, non-destructive equipments ( $\mathrm{X}$ rays, gamma imaging systems)) are integrated in the facility in order to propose to the customers a complete offer in terms of irradiation services.

\section{NEUTRON FLUXES AND GAMMA DOSES EVALUATION IN THE JHR ENVIRONMENT}

The irradiation devices which are embedded in the reactor (core and reflector) integrate different types of instrumentation permitting to follow on line the experimental parameters of the irradiation scenarios. These instrumentations can be classical (thermocouples, pressure gauges, flow meters) but can also be innovative (as cladding deformation sensors). Due to severe working constraints in the experimental devices (thermal-hydraulic conditions, gamma and neutron fluxes, 


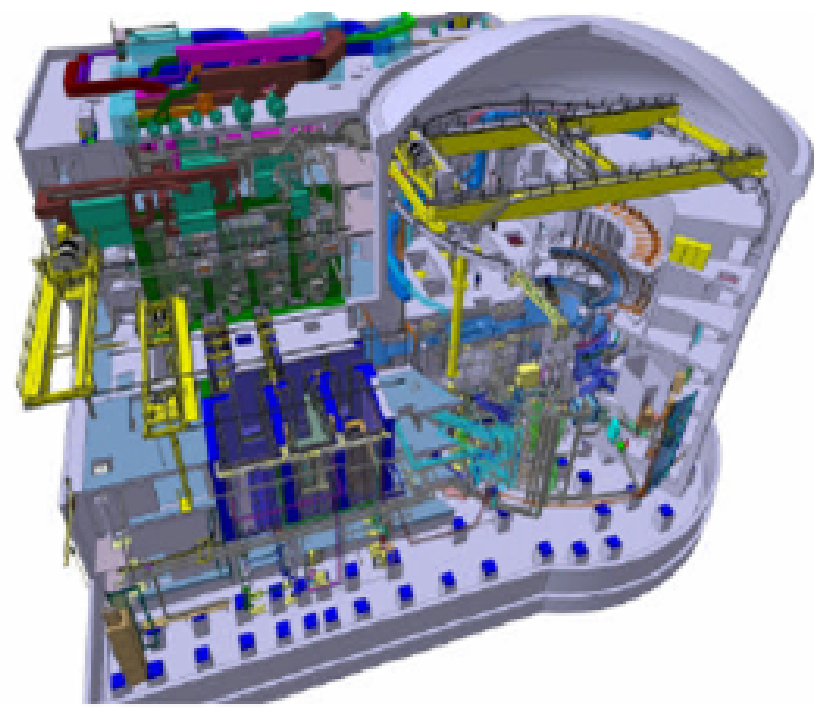

Fig. 1. Overview of the JHR facility.

lack of place), specific developments had to be engaged to obtain satisfying results in terms of scientific data (ex. creep phenomenon determination on irradiated materials samples). Direct integration of electronics in the device can give some advantages as measuring close to the samples and consequently limiting the effect of long lines between the sensors and the instrumentation and control rooms.

Concerning the use of WIFI modules, other interests are identified as:

- Limiting the number of lines between the in-pile and out of pile parts

- Simplifying the operation constraints, connexions, deconnexions, under water line manipulations

- Increasing the autonomy of the device.

An important remark: note that the use of WIFI modules concerns now only sensors dedicated to experimental issues and not safety-related ones (reliability aspects difficult to demonstrate).

In all cases, some instrumentation which integrates electronics modules can be sensible to neutron and gamma fluxes. Some verifications of behaviour under flux have to be performed prior to their use in order to define their limitation in terms of doses.

The first phase in this work was to estimate the dose levels in a research reactor in different zones where the electronic modules can be located. These doses viewed by the electronics can be due to relative short distance to the reactor core but also due to operation scenario (i.e., consequence of unloading an irradiated device from the core). This operation performed closed to the other devices in the reactor can affect the behaviour of electronics located in their head (i.e., upper part of the device).

\section{A. Neutron fluxes evaluation}

The calculations performed showed that the neutron effects become negligible in an external zone around the core higher than $2 \mathrm{~m}$. Electronics modules located in the head of the

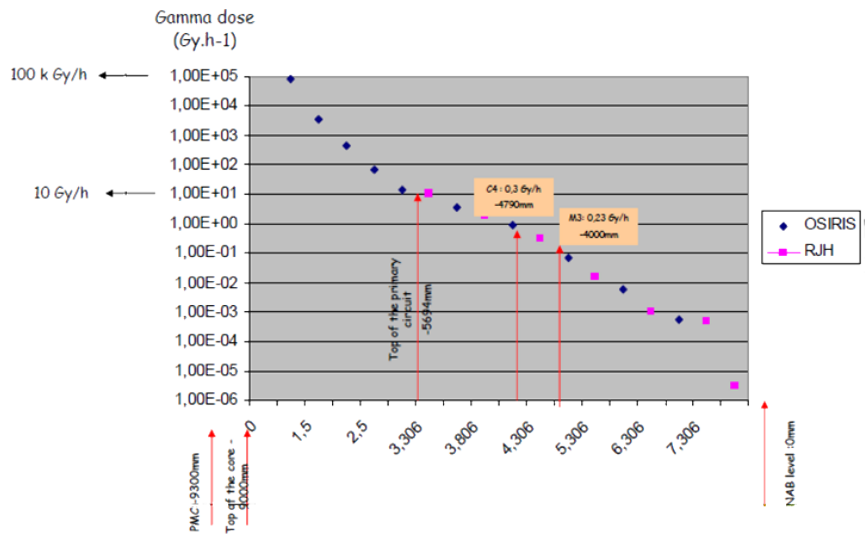

Fig. 2. Gamma dose rates (GRDR) estimation.

TABLE I

GENERIC FUNCTIONS OF AN INSTRUMENTATION CHAIN.

\begin{tabular}{ll}
\hline Description & Function \\
\hline Transducer & Detector (Sensitive element) \\
Sensor & Electrical signal generator \\
Connection & Signal transmitter \\
Converter & Electrical transducer \\
Terminal & Signal transmitter \\
& \\
Transmission & Wire connection \\
& Wireless connection \\
& WIFI emitter + receiver \\
Signal Processing & Signal shaping \\
Electrical connection & Electrical transmitter \\
Display & Signal reading \\
\hline
\end{tabular}

devices are in normal conditions not affected by the neutron flux.

\section{B. Gamma dose evaluation}

Fig. 2 gives the gamma dose calculation distribution $(\mathrm{Gy} / \mathrm{h})$ along the axis $(\mathrm{m})$ and compare the results to OSIRIS French reactor in the same conditions.

GRDR Gamma Rays Dose Rates normalised to $100 \mathrm{MW}$ fit very well with OSIRIS and JHR. In the region from the top of the core to 5-m above, GRDR decreases approximately by a factor 10 each metre.

\section{DESCRIPTION OF IRRADIATION REQUIREMENTS}

The physical values measured on the experimental loops (in-pile part) in the reactor pool are obtained via measurement chains between the transducer and data acquisition system.

The generic functions of an embedded measuring chain are recalled in Table IV. Besides, Table IV recalls the irradiation requirements for possible embedded electronic equipments in the JHR reactor pool.

\section{WIFI MODULES EXPERIMENTAL TESTS}

\section{A. Reminder of the context}

During the period [2006 to 2009], the FP6 Integrated Infrastructure Initiative MTR $+\mathrm{I} 3$ permitted to create a community on 
TABLE II

IRRADIATION LEVEL ESTIMATION IN JHR CORE ENVIRONMENT.

\begin{tabular}{|c|c|c|c|c|c|}
\hline 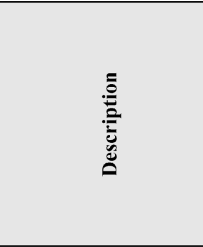 & & $\sum_{k}^{\circ}$ & 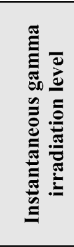 & 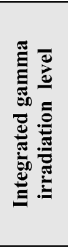 & 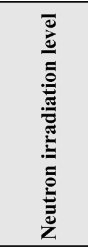 \\
\hline $\begin{array}{c}\text { Sensors } \\
\text { (transducer }+ \\
\text { integrated electronic } \\
\text { system) }\end{array}$ & 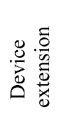 & 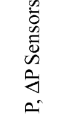 & $\begin{array}{c}0.3 \\
\text { Gy/h }\end{array}$ & $\begin{array}{c}13 \\
k G y\end{array}$ & Minor \\
\hline $\begin{array}{c}\text { Digital TC } \\
\text { multiplexers } \\
\text { Measurement } \\
\text { multiplexers on } \\
\text { power cables }\end{array}$ & 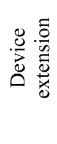 & 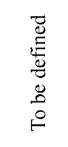 & $\begin{array}{l}0.3 \\
\text { Gy/h }\end{array}$ & $\begin{array}{c}13 \\
\text { kGy }\end{array}$ & Minor \\
\hline $\begin{array}{l}\text { Wireless WIFI } \\
\text { connection module }\end{array}$ & 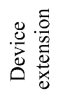 & 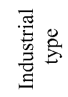 & $\begin{array}{l}0.3 \\
\text { Gy } / \mathrm{h}\end{array}$ & $\begin{array}{c}13 \\
\text { kGy }\end{array}$ & Minor \\
\hline $\begin{array}{c}\text { Mobile source in } \\
\text { front of embedded } \\
\text { electronic equipment } \\
\left(^{*}\right)\end{array}$ & 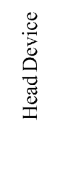 & 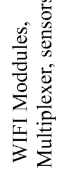 & $\begin{array}{c}6.4 \\
\mathrm{kGy} / \mathrm{h}\end{array}$ & $\begin{array}{l}106 \\
\text { Gy }\end{array}$ & $\begin{array}{l}\text { To be } \\
\text { specified }\end{array}$ \\
\hline
\end{tabular}

(*) Hypothesis: 1-minute exposure, 20-cm water layer between the source and electronic system.

Material Testing Reactors representing 18 countries [1]. One action of this program concerned the behaviour of electronics under radiation. This action was shared between CEA in France and ITN in Portugal. UCM in Spain was associated to this action due to relevant feedback about previous work performed with ITN on electronics for CERN applications. In this context, tests on behaviour on WIFI modules under flux have be identified for experimental data transmission because of innovative technique in Nuclear environment.

\section{WIFI MODULES SELECTION}

The most complete suite of WIFI technology solutions available in the industry are distributed in function of the transmission radio-frequency. The ISM frequencies (Industrial, Scientific and Medical) are bands reserved internationally for non commercial purposes. The highest frequency of ISM bands is $2.4 \mathrm{GHz}$. The ISM bands are generally used and the higher the frequency the more tolerant is the device, therefore $2.4 \mathrm{GHz}$ is the band chosen for the radio-frequency of the wireless device under test. Two types of modules called M1 \& M2 ${ }^{1}$ offer solutions for $2.4-\mathrm{GHz}$ band. They have been selected for these tests.

The demonstration kit from M1 is a good candidate for the irradiations because the microprocessor and other elements are fitted separated from de radio-frequency (RF) module and it would be easier to find the radiation tolerance of each component separately. Also, in order to test a wireless transmission device from another manufacturer on the market and

\footnotetext{
${ }^{1} \mathrm{M} 1$, M2 correspond to commercial modules types. For more precise information, contact the authors.
}

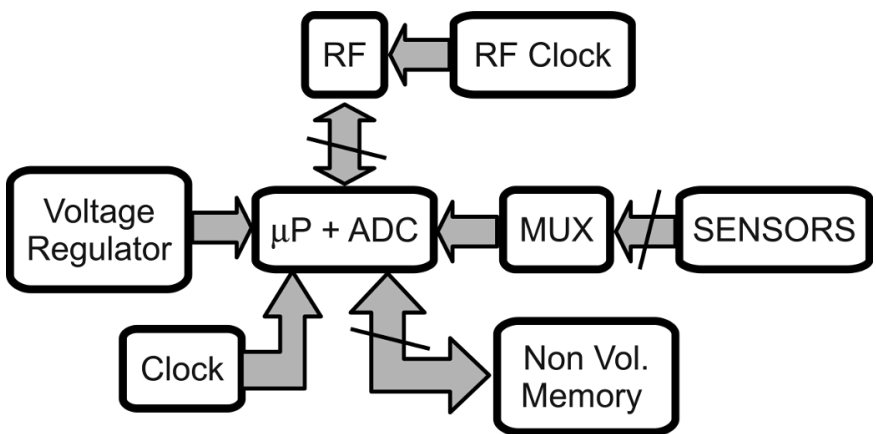

Fig. 3. General description of the main components on a WIFI card.

to compare their behavior under irradiation, a demonstration kit from M2 is chosen because of the high integration level that includes in the same chip the microprocessor, RF transceiver module and the flash memory. All these components are built in CMOS technologies.

Therefore, the possible damage induced by displacement is negligible since CMOS devices are majority carriers devices. However, it is well-known their sensitivity to ionising dose. Gamma or X rays and charged ions are liable to create electron-hole pairs that can be eventually trapped in the $\mathrm{SiO}_{2}$ layer leading to a MOSFET threshold voltage shift and the appearance of large leakage currents.

From the whole set of devices, the most sensitive device is the internal microprocessor. Although the scale of the CMOS technology is unknown, due to the large amount of gates and other circuits, its complexity is great and the integration high. Thus this device is the most sensitive to gamma radiation.

Other devices are the crystal oscillators. According to the literature, these are insensitive to permanent damage due to ionizing radiation. Indeed, transient changes of the resonance frequency are usually related to small temperature growth rather than the appearance of photoelectric currents.

Finally, other CMOS devices such as multiplexers, amplifiers and or gates are also affected by the radiation. However, these devices do not need a large scale of integration due to the low number of necessary transistors. Therefore, problematic issues such as the presence of leakage currents are not liable to occur making the devices more tolerant to the ionizing radiation.

\section{A. Experimental tests performed with ${ }^{60}$ Co source and RPI reactor at ITN}

The Portuguese Research Reactor (RPI) is a 1-MW pooltype reactor, operating since 1961. A fast neutron irradiation facility was built at the RPI to test commercial electronic components for CERN within a program started in 1999 [2]. This facility currently allows irradiating electronic modules with fast neutron fluxes (E $>1 \mathrm{MeV}$ ) up to $4 \cdot 10^{8} \mathrm{n} / \mathrm{cm}^{2} / \mathrm{s}$; the simultaneous gamma dose rate is up to $60 \mathrm{~Gy} / \mathrm{h}$. Complementary irradiations were performed in an industrial ${ }^{60} \mathrm{Co}$ source, allowing gamma dose rates up to $10 \mathrm{kGy} / \mathrm{h}$. WIFI modules were irradiated in a secondary irradiation position, at a gamma dose rate of approximately $200 \mathrm{~Gy} / \mathrm{h}$. 


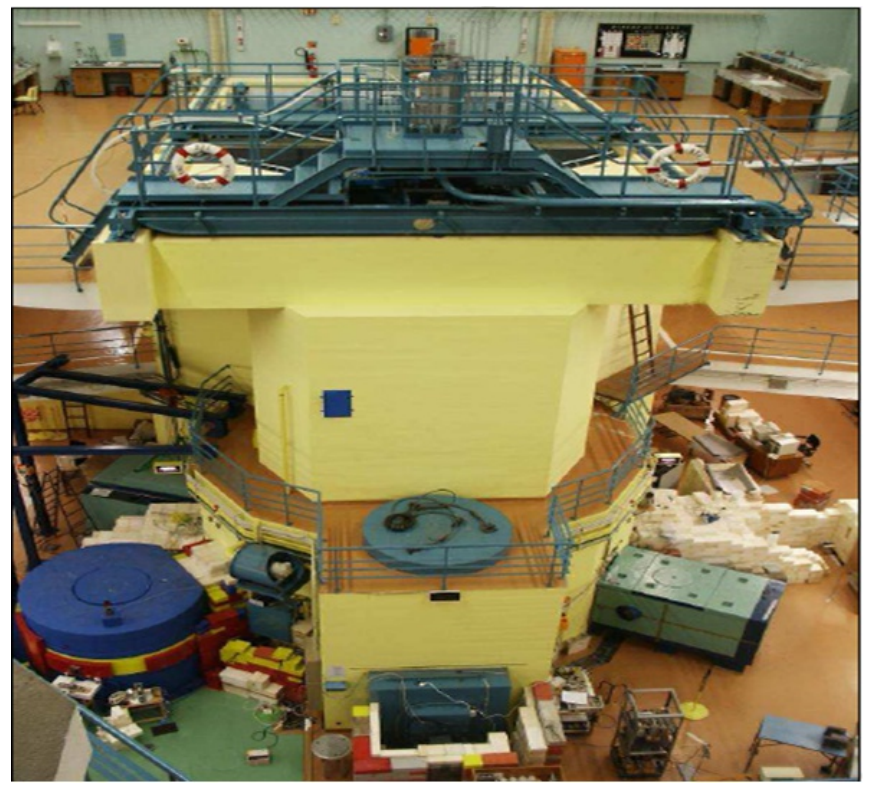

Fig. 4. Overview of the RPI reactor.

\section{B. Results}

The different tests performed on WIFI modules under neutron and/or gamma radiation gave the results summarized in Table VI-B.

The results of the tests for the M1 and M2 modules show that the microprocessor (or acquisition module) is the most sensitive component of the entire device and fail after 500 Gy (@300Gy/h) in both cases. The results also show that the $\mathrm{RF}$ transceiver module (M1) is more tolerant to the radiation and continues to run after $3.8 \mathrm{kGy}$ (@300Gy/h). The final conclusions is that M1 shows better performance and it is necessary to use shielding data acquisition module separated from the RF module.

Other exploratory tests were done with Pt-100 temperature sensors from M3. These temperature sensors, not intended for applications under radiation, use XBEE RF modules. The sensors were irradiated in the RPI with a neutron fluence of $4 \cdot 10^{12} \mathrm{n} / \mathrm{cm}^{2}$ and a gamma dose of $210 \mathrm{~Gy}$ without any degradation. While the neutron fluence exceeded the necessary for the tests for the JHR, the gamma dose was toolow; therefore sensors were also irradiated in the ${ }^{60} \mathrm{Co}$ source of ITN. A clear degradation of the in-board power supplies was visible after $200 \mathrm{~Gy}$ and the devices ceased working after approximately $600 \mathrm{~Gy}$. The RF modules werealso irradiated without power being applied and showed a better radiation behaviour: after 1 $\mathrm{kGy}$, the XBEE modules were still operational but failed after 2 kGy.

\section{Recommendations}

Using these results, several recommendations have been proposed based on feedback issued on these WIFI gamma tolerance tests and are included in Table VI-C.

From the results obtained from this work on WIFI modules gamma tolerance tests, some proposals have been performed
TABLE III

EXPERIMENTAL RESULTS ON RADIATION TOLERANT TESTS. MX ARE COMMERCIAL MODULES.

\begin{tabular}{|c|c|c|c|}
\hline Module & $\begin{array}{c}\text { Test } \\
\text { facility }\end{array}$ & $\begin{array}{l}\text { Experimental } \\
\text { scenario }\end{array}$ & Comments \\
\hline M1 & $\begin{array}{l}\text { ITN-Co }^{60} \\
\text { source }\end{array}$ & $\begin{array}{l}\text { Gamma: } 3 \mathrm{kGy} \\
\quad(200 \mathrm{~Gy} / \mathrm{h}) \\
\text { Gamma:1.6 kGy } \\
\quad(200 \mathrm{~Gy} / \mathrm{h})\end{array}$ & $\begin{array}{l}\text { Trouble on acquisi- } \\
\text { tion modules } \\
\text { RF modules resis- } \\
\text { tant at } 3.3 \mathrm{kGy} \\
\text { Performance better } \\
\text { than XBEE RF mod. }\end{array}$ \\
\hline M2 & $\begin{array}{l}\text { ITN-Co }^{60} \\
\text { source }\end{array}$ & $\begin{array}{l}\text { Gamma: 710Gy } \\
(284 \mathrm{~Gy} / \mathrm{h})\end{array}$ & $\begin{array}{l}\text { No degradation up to } \\
710 \mathrm{~Gy} \\
\text { Microprocessor } \\
\text { failed at } 0.45 \mathrm{kGy}\end{array}$ \\
\hline M2 & $\begin{array}{l}\text { ITN } \\
\text { reactor }\end{array}$ & $\begin{array}{c}\text { Gamma: } 225 \mathrm{~Gy} \\
\text { Neutron: } 5.10^{12} \\
\mathrm{n} / \mathrm{cm}^{2}\end{array}$ & $\begin{array}{l}\text { Results for gamma } \\
\text { and neutron tole- } \\
\text { rance }\end{array}$ \\
\hline $\begin{array}{c}\text { M3 } \\
\text { XBEE } \\
\text { module }\end{array}$ & RPI & $\begin{array}{l}\text { Gamma: 120Gy } \\
(10 \mathrm{~Gy} / \mathrm{h}) \\
\text { Neutron: } 4 \times 10^{12} \\
\mathrm{n} / \mathrm{cm}^{2} \\
\left(1 \times 10^{8} \mathrm{n} / \mathrm{cm}^{2} / \mathrm{s}\right)\end{array}$ & $\begin{array}{l}\text { No degradation in } \\
\text { performance. }\end{array}$ \\
\hline $\begin{array}{c}\text { M3 } \\
\text { XBEE } \\
\text { module }\end{array}$ & $\begin{array}{c}\text { ITN-Co }^{60} \\
\text { source }\end{array}$ & $\begin{array}{l}\text { Gamma: 600Gy } \\
(200 \mathrm{~Gy} / \mathrm{h})\end{array}$ & $\begin{array}{l}\text { Degradation of } \\
\text { voltage regulator } \\
\text { after } 200 \mathrm{~Gy} \text {. } \\
\text { Failure of micro- } \\
\text { processor at } 600 \mathrm{~Gy} \text {. }\end{array}$ \\
\hline $\begin{array}{c}X B E E \\
R F \\
\text { module }\end{array}$ & $\begin{array}{c}\text { ITN-Co }^{60} \\
\text { source }\end{array}$ & $\begin{array}{c}\text { Gamma: } 1 \mathrm{kGy} \\
(200 \mathrm{~Gy} / \mathrm{h})\end{array}$ & $\begin{array}{l}\text { Better performance } \\
\text { when power supply } \\
\text { is disconnected } \\
\text { during irradiation. }\end{array}$ \\
\hline
\end{tabular}

on a possible application concerning materials irradiation capsule embedded in a material testing reactor.

The WIFI module (transmitter) is to be located on the head of the capsule transfers data (e. g., temperature sensors) up to out of pile part (receiver).

The gamma tolerance results obliged to remove the acquisition cards from the core and to shield it. Nevertheless, some electrical lines (supper standard lines-serial type) are necessary (but limited) between the out of pile and in pile part in order to drive the electronic card as described below:

1) Line for power supply.

2) Lines for transmission protocol.

3) Line for ground.

Finally, a test of location RF transmitter in the water versus depth has also to be checked in order to determine the lower acceptable level for correct transmission.

\section{CONCLUSIONS AND PERSPECTIVES}

This experimental work shared between CEA, ITN and UCM allow exploring the WIFI modules behaviour under flux. The first results obtained based from COTS approach indicate that the Radio Frequency (RF) module is well resistant (gamma source up to $3.5 \mathrm{kGy}$ ). Nevertheless, the acquisition 
TABLE IV

RECOMMENDATIONS ABOUT WIFI MODULES USE.

\begin{tabular}{|c|c|c|}
\hline Item & Type & Recommendations \\
\hline \multirow[t]{5}{*}{$\begin{array}{l}\text { Electronic } \\
\text { Components }\end{array}$} & RF module & $\begin{array}{l}\text { Prefer module working at high } \\
\text { frequency (ex: ISM } 2.4 \mathrm{GHz} \text { ). } \\
\text { Gamma tolerance hi-gher than } 3.5 \\
\text { kGy. }\end{array}$ \\
\hline & Multiplexer & Tolerant to gamma irradiation \\
\hline & $\begin{array}{l}\text { Acquisition } \\
\text { module }\end{array}$ & $\begin{array}{l}\text { Gamma tolerance lower ( } 500 \mathrm{~Gy}) \\
\text { critical components: } \\
\text { microprocessor \& controller } \\
\rightarrow \text { Prefer protected location } \& \\
\text { foreseen shielding. }\end{array}$ \\
\hline & Flash RAM & $\begin{array}{l}\text { Prefer CMOS technology which is } \\
\text { more tolerant to neutrons }\end{array}$ \\
\hline & $\begin{array}{l}\text { Voltage } \\
\text { regulator }\end{array}$ & $\begin{array}{l}\text { Prefer to work without it } \\
\text { (sometimes, it is necessary for } \\
\text { microprocessor work in stable } \\
\text { conditions) }\end{array}$ \\
\hline
\end{tabular}

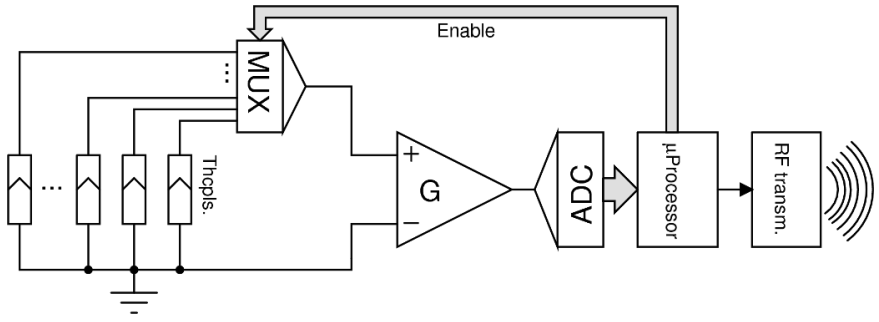

Fig. 5. Simplified drawing of wireless transmission chain proposal (Ex: Irradiation capsule equipped with thermocouples).

modules (microprocessor and controller) failed at a relatively low gamma level (500 Gy).

For application in the JHR, the rough estimatation of the radiation dose levels of embedded electronics modules and detectors indicates that shielding will be necessary to drop radiation-dose levels below an acceptable threshold in order to warranty their reliability during operation.

This irradiation resilience can be provided either with protective bulk shielding materials or use of hardened electronic or a combination of both.
TABLE V

NECESSITY OF SHIELDING.

\begin{tabular}{ll}
\hline Dose level & Shielding \\
\hline$<10 \mathrm{~Gy}$ & No shielding \\
$10-100 \mathrm{~Gy}$ & To be assessed \\
$>100 \mathrm{~Gy}$ & Necessary
\end{tabular}

TABLE VI

NECESSITY OF SHIELDING.

\begin{tabular}{lll}
\hline Equipment & $\begin{array}{l}\text { Integrated gamma } \\
\text { dose in 10 years }(\mathbf{G y})\end{array}$ & $\begin{array}{l}\text { Equivalent } \mathbf{P b} \\
\text { shielding }(\mathbf{c m})\end{array}$ \\
\hline Irradiation device type & $13 \mathrm{kGy}(13140)$ & 6.7 \\
\hline
\end{tabular}

Another option would be to locate electronics boards far from the gamma sources in order to limit gamma impacting doses.

A final remark: Requirements for shielding depending on the dose level, for ordinary components, can be taken up from Table VII.

From the characteristics given before, we can deduce the shielding thickness that would lead to an acceptable integrated dose (100 Gy) on electronics boards as those of Table VII.

As conclusion of this exploration tests on WIFI modules, their use in a research reactor environment induce a strong expertise of the electronics components which can impose some adaptations (choice of specific technology as CMOS, shielding or distance increase from the gamma sources).

Nevertheless, the use of WIFI module can be interesting in an industrial facility for wireless information transfer from a sensor located in a circuit (as flow meter, pressure sensor, level sensors).

\section{REFERENCES}

[1] J. Dekeyser, and D. Iracane "Integrated infrastructure initiatives for material testing reactor innovations," Proceedings of the $7^{\text {th }}$ European Commission Conference on Euratom research and training in reactor systems (FISA2009), pp. 526-547, Prague (Czech Republic), June 2009.

[2] F. J. Franco, Y. Zong, J. A. de Agapito, J. G. Marques, A. C. Fernandes, J. Casas-Cubillos, and M. A. Rodriguez-Ruiz, "Radiation tolerant D/A converters for the LHC cryogenic system," Nuclear Instruments and Methods in Physics Research Section A: Accelerators, Spectrometers, Detectors and Associated Equipment, vol. 553, no. 3, pp. 604-612, Nov. 2005. 